\title{
Red de Espacios Culturales de Andalucía
}

Javier Verdugo Santos, Coordinador de los Conjuntos Arqueológicos y Monumentales. D.G. de Bienes Culturales. Consejería de Cultura de la Junta de Andalucía

\section{La RECA integrará a los} Conjuntos

Arqueológicos y

Monumentales y a los

actuales enclaves que

se agrupan en torno a

la RAYA
Espacio Cultural y Zona Patrimonial

La Ley 14/2007, de 26 de noviembre, del Patrimonio Histórico de Andalucía (BOJA, no 248 de 19 de diciembre de 2007) establece en su artículo 75 que forman parte de las Instituciones del Patrimonio Histórico, los denominados Espacios Culturales, que se definen en el artículo 76 como "aquellos inmuebles de titularidad pública o privada inscritos en el Catálogo General del Patrimonio Histórico Andaluz, 0 agrupaciones de los mismos, que por su relevancia o significado en el territorio donde se emplazan se acuerde su puesta en valor y difusión al público". Es decir, la nueva ley contempla una nueva figura de gestión del patrimonio, junto con los museos, las bibliotecas y los archivos. Estos Espacios Culturales se clasifican en Conjuntos y Parques Culturales. De este modo consolida los Conjuntos ya contemplados en la Ley $1 / 91$, añadiéndoles la obligación de dotarse de un plan director y de un órgano de gestión propio, e incorpora la figura de los Parques Culturales que se definen en el artículo 81 como "aquellos que abarcan la totalidad de una o más Zonas Patrimoniales que por su importancia cultural requieran la constitución de un órgano de gestión en el que participen las administraciones y secto- res implicados". Dos condiciones se imponen para su formulación, la primera la existencia de una o más Zonas Patrimoniales y la segunda, su importancia cultural. Precisamente esta categoría de protección es otra de las novedades de la naciente Ley que recoge la relación entre el patrimonio y territorio. Las Zonas Patrimoniales se definen en el artículo 26.8 como "aquellos territorios o espacios que constituyen un conjunto patrimonial, diverso y complementario, integrado por bienes diacrónicos representativos de la evolución humana, que poseen un valor de uso y disfrute para la colectividad y, en su caso, valores paisajísticos y ambientales". La Zona Patrimonial es por tanto un Bien de Interés Cultural que constituye un conjunto patrimonial diverso y diacrónico, cuya declaración comporta su inscripción en el Catálogo General del Patrimonio Histórico Andaluz.

La estructura y órgano de gestión de un Parque Cultural, de acuerdo con lo previsto en el artículo 82, vienen establecidos en su norma de creación pudiendo adoptar cualquiera de las formas con 0 sin personalidad jurídica prevista en la legislación. Podemos tener, por tanto, parques culturales que funcionen a través de una fundación, un organismo autónomo, una 


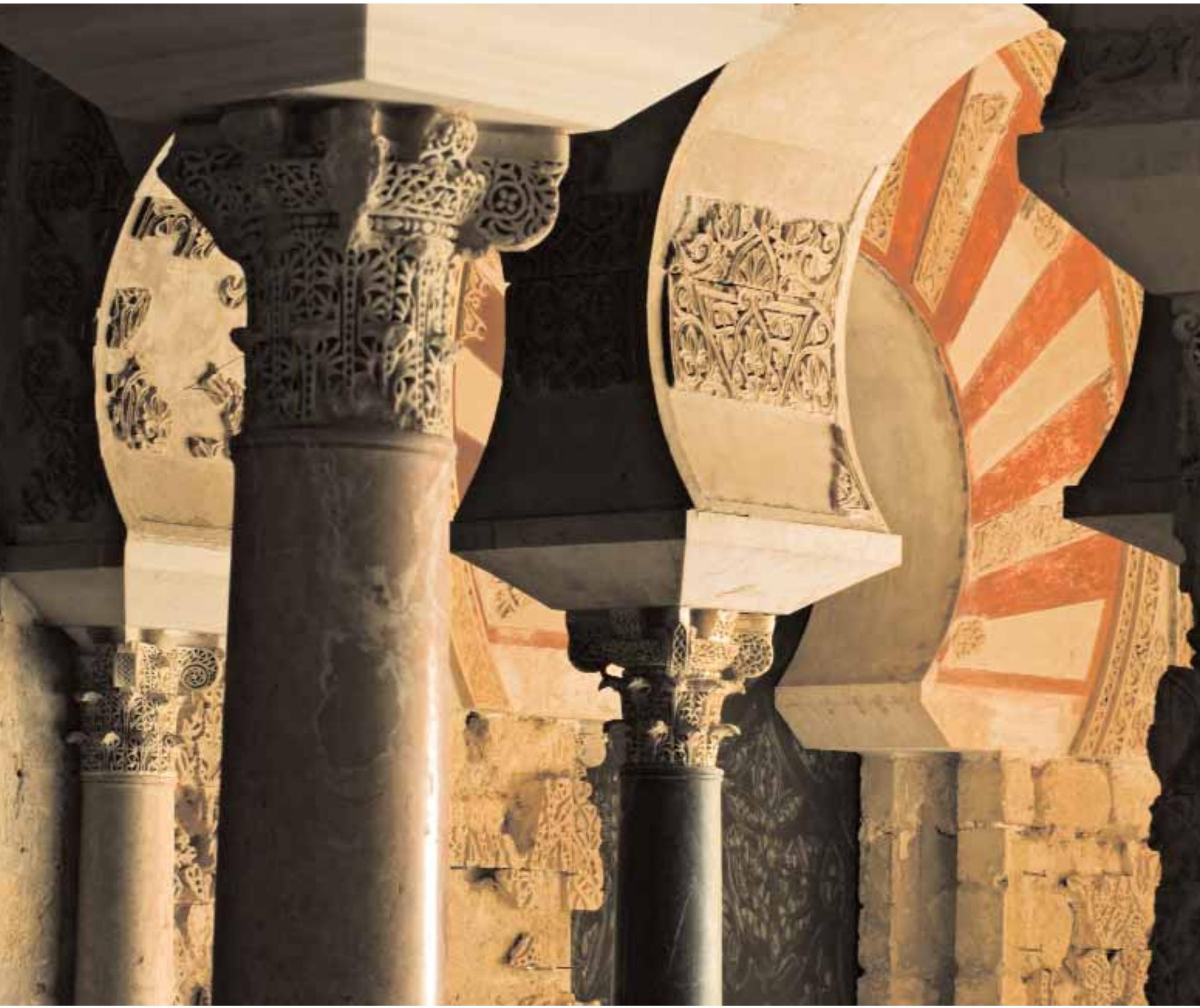




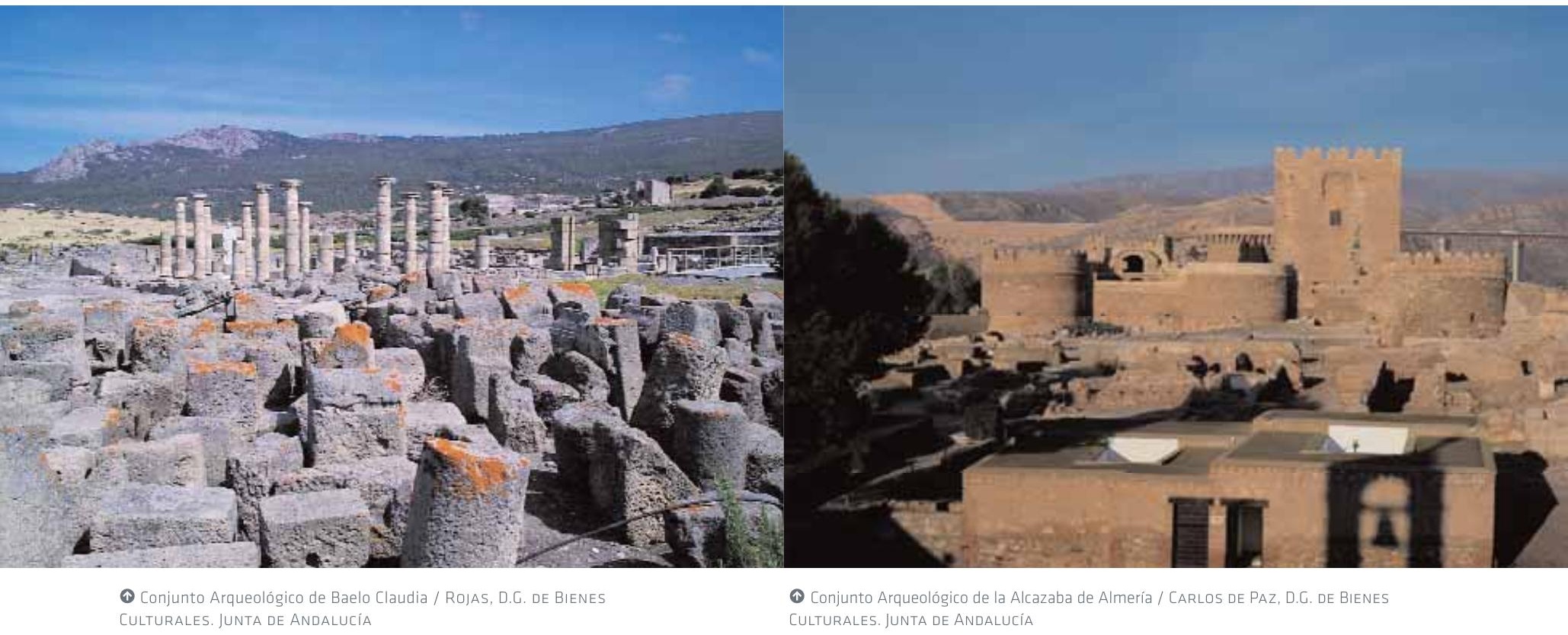

(1) Conjunto Arqueológico de Baelo Claudia / RojAS, D.C. DE BIEnES CUlturales. Junta de Andalucía

La existencia de la red significa que sólo aquellos espacios o enclaves que la Consejería determine forman parte del sistema 


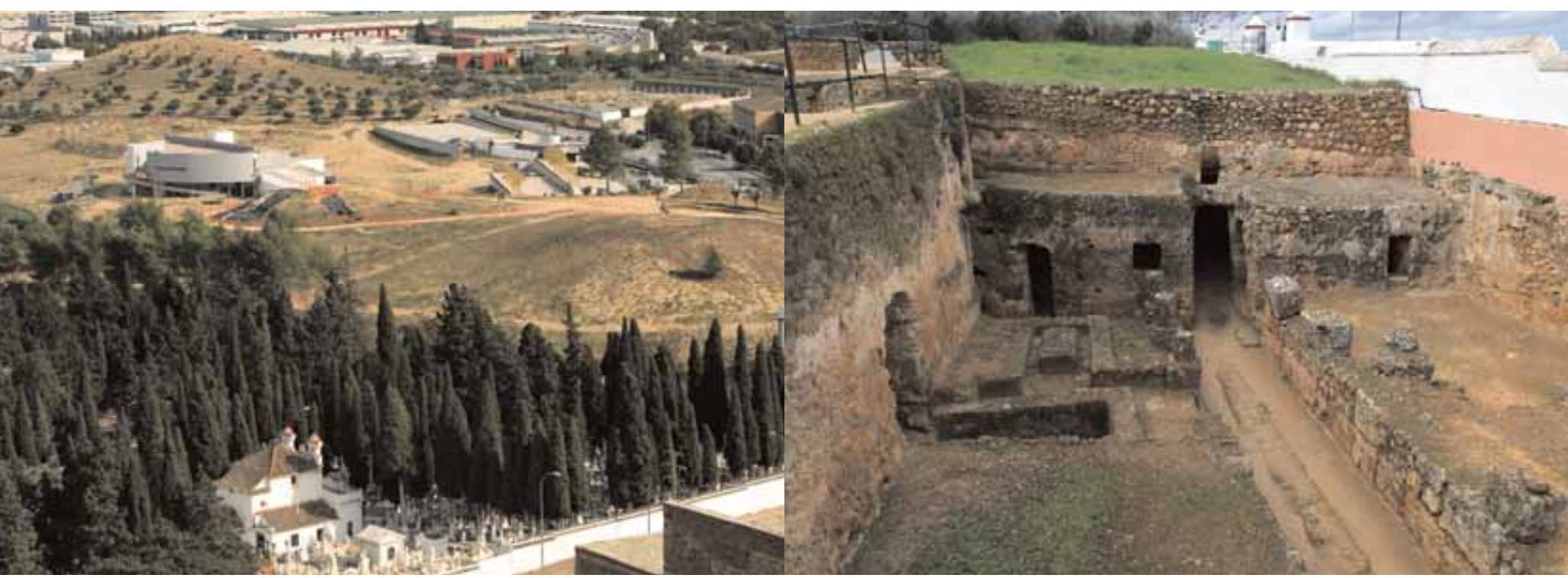

(1) Cementerio de Antequera (Málaga), túmulo del Dolmen de Menga y Centro de Interpretación de la Prehistoria en Andalucía / JAVIER PÉREz GonZÁLEZ, IAPH

(1) Tumba del Elefante. Conjunto Arqueológico de Carmona (Sevilla) / Guillermo MENDo, D.C. de Bienes Culturales. Junta de Andalucía

oficina técnica o uno de los consorcios interadministrativos previstos en el artículo 95 de la nueva Ley de Patrimonio 0 a través de las llamadas "entidades instrumentales" dispuestas en la reciente Ley $9 / 2007$, de 22 de octubre, de la Administración de la Junta de Andalucía (BOJA, $n$ -215, de 31 de octubre de 2007).

La Red de Espacios Culturales de Andalucía

La nueva ley de patrimonio histórico en su articulo 83 crea la Red de Espacios Culturales de Andalucía (RECA) constituida por un "sistema integrado y unitario formado por aquellos Espacios Culturales ubicados en el territorio de la Comunidad Autónoma que sean incluidos en la misma por la Consejería competente en materia de patrimonio histórico, así como aquellos enclaves abiertos al público que por sus condiciones y características no requieran la dotación de un órgano de gestión propio". La existencia de la red significa que sólo aquellos espacios o enclaves que la Consejería determine forman parte del sistema.
Los Espacios Culturales que se integren en la RECA estarán constituidos por aquellos inmuebles de titularidad pública o privada inscritos en el Catálogo General del Patrimonio Histórico Andaluz, o agrupaciones de los mismos, que por su relevancia o significado en el territorio donde se emplazan se acuerde su puesta en valor y difusión al público. Es decir deberán estar inscritos como Bien de Interés Cultural o Bien de Catalogación General, que son las dos figuras de protección contempladas en el articulo 7 de la nueva Ley 14/2007, de 26 de noviembre.

En una aproximación a la futura organización de la Red de Espacios Culturales de Andalucía, que deberá ser objeto de desarrollo reglamentario de acuerdo con el mandato del artículo 83.2 de la nueva Ley, podemos afirmar que la RECA integrará a los Conjuntos Arqueológicos y Monumentales dependientes de la Consejería de Cultura y a los actuales enclaves que se agrupan en torno a llamada Red de Yacimientos Arqueológicos de Andalucía (RAYA). 

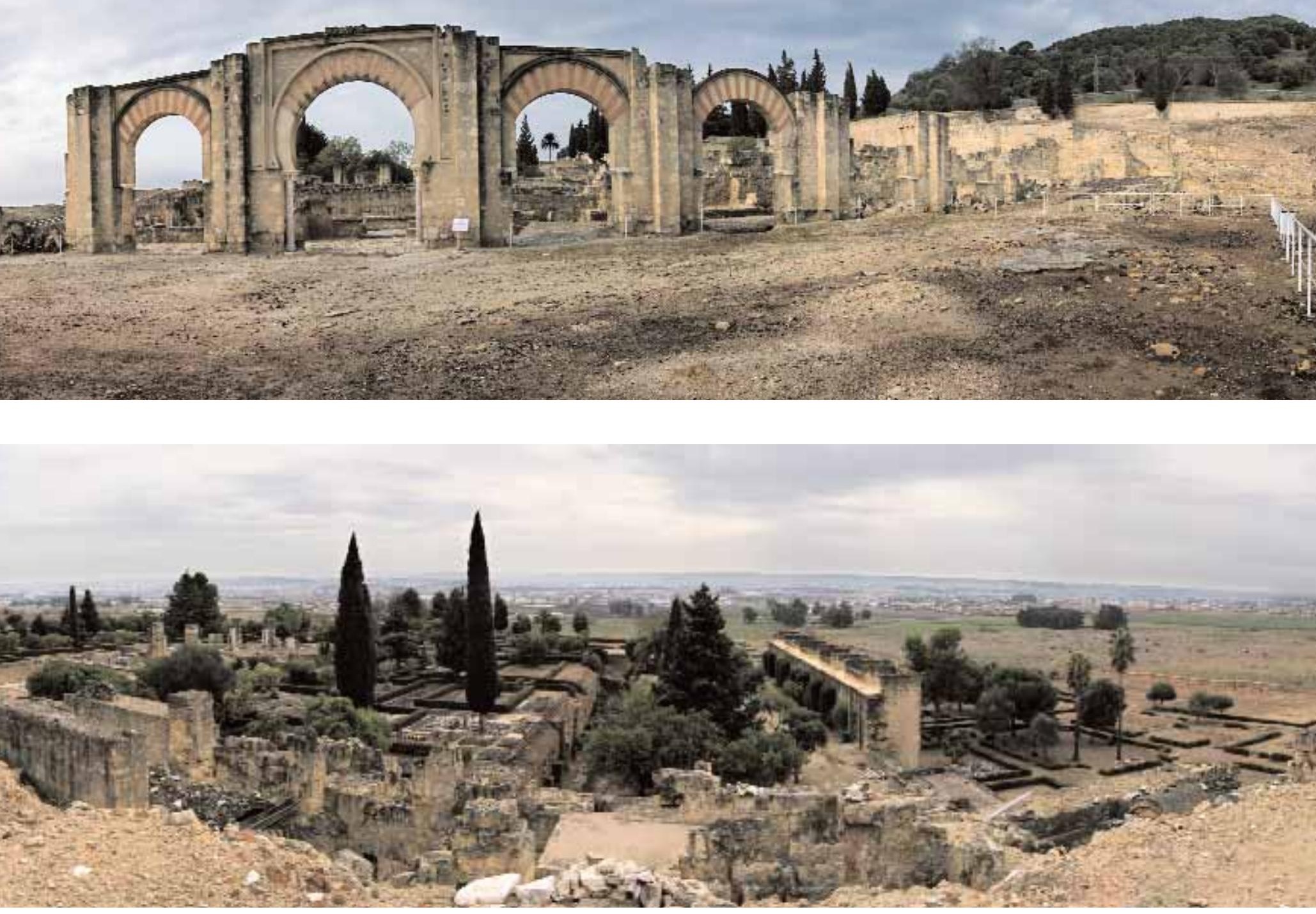

(1) Pórtico del Alcázar y Jardín Alto del Conjunto Arqueológico de Madinat al-Zahra / JuAN CARLos CAZALLA, IAPH 
Entre sus objetivos se encontrarán:

a) La coordinación de los sistemas generales de gestión de los espacios y parajes culturales integrados en la Red a través de los correspondientes planes directores.

b) La promoción externa de los espacios culturales y parajes integrados en la Red de forma homogénea y conjunta.

c) La colaboración en programas estatales e internacionales de conservación de espacios y parajes culturales de similar naturaleza, que posean un valor de uso y disfrute para la colectividad.

d) El intercambio de información con otras redes o sistemas de protección del patrimonio histórico, así como con aquellas organizaciones nacionales o internacionales relacionadas con la protección, conservación y puesta en valor de espacios y parajes culturales de similar naturaleza.

e) El fomento de las buenas prácticas en la protección y gestión del patrimonio histórico entendido como parte del ecosistema humano, a través de la puesta en valor y dinamización de los espacios y parajes culturales de la Red.

f) La promoción y desarrollo sostenible de los espacios y parajes culturales integrados en la Red en función de sus valores y singularidades, la diversidad cultural y el desarrollo local.

La Red de Espacios Culturales de Andalucía se articulará en tres ejes:

a) El aprovechamiento sostenible de los espacios y parajes como recursos culturales a través de su tutela, conservación y puesta en valor. b) El fomento del conocimiento científico de sus valores generando su investigación.

c) El impulso de iniciativas de desarrollo local y territorial basada en la difusión y revalorización de los espacios y parajes culturales integrados en la Red.

La Red de Espacios Culturales de Andalucía podrá incardinarse total o parcialmente en otras redes similares de ámbito territorial superior, ya sean nacionales, transnacionales o europeas.
En cuanto a su funcionamiento, la Red de Espacios Culturales de Andalucía debe constituirse como un programa transversal de la Consejería de Cultura adscrito a la Dirección General de Bienes Culturales que se desarrollaría desde el Servicio de Investigación y Difusión del Patrimonio Histórico, en coordinación y cooperación con los otros servicios de la Dirección General de Bienes Culturales, Secretaría General Técnica, Delegaciones Provinciales, y especialmente el Instituto Andaluz del Patrimonio Histórico y la Empresa Pública de Gestión de Programas Culturales quienes mediante las oportunas encomiendas de funciones podrán participar en el asesoramiento y gestión de los espacios y enclaves culturales integrados en la red.

Su organización deberá estructurarse a través de una Coordinación General, una Comisión Técnica y un Plan Director de la Red que servirá de instrumento de planificación y que deberá diseñar su ordenación en el territorio; las líneas estratégicas y los programas necesarios para el cumplimiento de los objetivos dirigidos de manera especial al aprovechamiento sostenible de los espacios y enclaves como recursos culturales a través de su tutela y valorización; al fomento del conocimiento científico de sus valores fomentando su investigación y al impulso de iniciativas de desarrollo local y territorial basadas en la difusión de los espacios y enclaves integrados en la Red. Junto al Plan Director de la RECA y de acuerdo con sus directrices se redactará un plan director por cada uno de los espacios y enclaves en ella incluidos.

En lo referente a la inclusión o cancelación de un espacio o un enclave cultural en la Red de Espacios Culturales de Andalucía, aquella se realizará de oficio por resolución de la persona titular de la Consejería de Cultura. También podrá solicitarse a instancia de parte la inclusión de un determinado espacio o enclave cultural en la Red, de acuerdo con el procedimiento que reglamentariamente se establezca. 